\title{
Using stories to understand clinical placement learning: a pilot study
}

\section{Kirsten Jack}

Manchester Metropolitan University, UK

\section{Claire Hamshire}

Manchester Metropolitan University, UK

\section{Abstract}

This pilot study explored the value of story writing to understand the learning needs of undergraduate nursing students during their first clinical placement. Early findings suggest that story writing affords freedom to express ideas and feelings, and could be used as an additional method alongside the current placement evaluation questionnaire to understand students learning needs.

Keywords: clinical placement; stories; learning needs; student nurses.

\section{Introduction}

This pilot study explored the value of using story writing to understand the learning needs of undergraduate nursing students during their first clinical placement. Stories were chosen as we believed that listening to the students describe and construct their experiences would be key in enhancing our understanding. Telling stories, in their own words, enabled students to detail whatever experiences were important to them as individuals. 


\section{Background/ Rationale}

The pilot study involved first year undergraduate nursing students on the Adult Nursing branch of the BSc (Hons) Nursing programme at Manchester Metropolitan University. Practice learning is integral to the educational development of pre-registration nursing students and contributes to fifty percent of the pre-registration programme hours in the UK (NMC, 2010) and thirty to fifty percent of undergraduate programmes Europe wide (Warne et al., 2010). The reality of the nursing programme can invoke anxiety (Cheung and Au, 2011) and the first clinical placement is particularly important for undergraduate nurses and one which can cause high levels of stress which negatively impacts on learning (Khater et al, 2014).

Learning in the clinical context is not restricted to theoretical competence but to the development of a professional identity as a nurse. The first clinical placement is critical to the socialisation process and some students do not feel prepared and can be unsure about what is expected of them (Andrew et al., 2009). Perceived lack of competence can be extremely stressful for students (Gorostidi et al., 2007) and they can often feel unwanted, with the desire to get through the placement day being greater than trying to learn anything (Levett-Jones et al., 2009). Placement learning in England is facilitated by a named mentor, who is expected to work with a student nurse for forty percent of the week (NMC, 2010). Hamshire et al., (2013) suggest that a supportive mentor is crucial to student progression although placement areas are frequently understaffed and mentors can be too busy to support students learning (McGowan, 2006). A combination of lack of time and inadequate support can have a negative effect on students' clinical learning experiences (Anthony and Yastick, 2011).

Currently we understand students' clinical learning experiences using feedback from a placement evaluation form, completed online, on completion of the placement block. The form consists of twenty statements covering a range of aspects, for example: how welcome the student was made to feel on the placement; how much evidence was used to inform practice and an overall statement about enjoyment during the placement experience. Evaluatory statements directly focussed on student learning include 'I was actively encouraged to observe/undertake new activities relevant to my agreed learning needs' and 'my individual learning needs were recognised and help was given with my learning outcomes, action plans, goals and achievement'. Students evaluate the 
placement using a five point Likert scale and have a small amount of space at the end of the questionnaire in which to write some free text comments relating to the evaluatory statements. This method is viewed as an effective way to support quality-learning environments. However it does little to help educators understand students' individual learning experiences and places a focus on what educators believe to be important, rather than trying to understand the individual learning needs of the student and the influences on these.

When trying to understand the factors that support and impede student placement learning, a more holistic approach seems beneficial. Students do not learn in a vacuum and are influenced by multiple factors which might not directly relate to the placement itself. For example: family problems, travelling difficulties and poor self-esteem can influence the ways students learn and the developmental opportunities they seek. We agree with Killam and Heerschap (2013, p.684) who advocate a more holistic approach to exploring this aspect of education, which is required to 'capture the complex interplay of factors which may hinder student learning'.

\section{Method}

To capture the multifaceted nature of student placement learning we used a method suggested by Orland-Barak and Wilhelem (2005, p.458) who explored how novice nurses learn the practice of nursing, using story writing. The participants in the study were asked to 'tell their stories of experience' at the end of the placement experience. We wanted to replicate this method as it allowed the participants the freedom to write freely and would add another dimension to the current evaluation form.

Stories (or narratives) have been used as a means of communicating experience for centuries (Koch, 1998) and as described by Frank (2010, p.21):

People have experiences - something happens - and then they tell stories that represent those experiences.

People live stories and, through the telling of them, make sense of their lives (Holstein and Gubrium, 2000). Using this method preserves the holistic nature of the experience and 
enables students to focus on key personal events, describing their experiences, rather than following an agenda set by educators. To provide an initial focus, the students were asked to describe a meaningful aspect of nursing practice or an incident that had occurred during their practice experience. We hoped that this would lead to a greater understanding of their learning needs during their first clinical placement.

Three weeks before the first clinical placement, the students were given a written information sheet outlining the nature of the pilot evaluation and the rationale behind it. The students were selected from one personal tutor group. We explained the nature of the study to the students and they were given two weeks to consider their involvement. Eight completed stories were returned from an initial group of ten female students, with an age range of twenty to thirty six years.

\section{Results}

Informal verbal student feedback on the story writing process was positive. The stories revealed that there are many factors, which impede and support student learning and this method provided us with a helpful insight into the factors influencing clinical learning development. Data analysis was undertaken, using a process similar to that of the framework analysis of Spencer et al. (2013) and Ritchie and Spencer (1994), with a phase of familiarisation followed by indexing, mapping and interpretation of the data, leading to the development of a thematic framework. Thus, the data was read and reread and emerging themes were noted. Some of the data from this pilot study is presented below.

\section{Lack of knowledge}

Perceived lack of knowledge can have a negative impact on confidence and can be a cause of worry. One student said:

I thought I was confident until I started my placement. I thought I have a very long way to go to catch up with the qualified nurses. Even though I was in training and a novice, I felt useless and I thought to myself, I will never know what is going on in practice. 
Another stated:

I am worried about the right and wrong things to say to patients when talking to them, either about their illness or in general conversation.

\section{Effective Mentorship}

One student wrote about the value of having a supportive mentor to guide learning, although acknowledged that the busy environment could affect the amount of time spent with her:

My main priority is to be a safe practitioner and my thoughts are in relation to nursing practice. As I began to feel confident and at ease with my mentor, I was able to think about situations and how I might approach new challenges...I have felt that my mentor has been a tremendous help to my immediate concerns and experiences. If I did get an opportunity to sit with her (a rare thing, as we were so busy) I found her knowledge and experience a positive influence in any new experience.

\section{Senior Students}

Senior students can support novices in practice and can use their own placement learning experiences as a guide to the process. As one student noted:

The Year Three students have helped me a lot in practice. I have learnt from them how they went about things themselves to get to where they are now. Through their advice, I take some of the plain paperwork home, to familiarise myself with it. This has really helped my confidence.

\section{Family Members}

One student described how she used her mother, who was also a health professional, to support her placement learning. She stated:

If it is something personal I don't like sharing deep feelings because I like how I am on the surface and I don't like looking weak. My mum is a nurse practitioner and 
speaking to her about situations puts things in perspective about nursing and what other people tell me to do, in regards to what I think is right.

\section{Placement Staff}

Placement staff can have a negative impact on effective clinical learning and too much support and not enough challenge can be problematic. The following student seemed to be struggling with her role identity, which is an important part of learning development for a student nurse:

The biggest threat to my development is the team I am in. Many of them are endlessly supportive and encouraging and when working with them I feel too comfortable. However some members make me feel that I am expected to play a particular role in the team and I am struggling to find out what this is, and how to contribute. At times I feel that my lack of knowledge and experience is inconveniencing them. I very briefly aired some of my views in a conservative manner, and some supportive team members explained that, 'I shouldn't know that yet'....the responses of those with the most experience have been the most helpful.

\section{Conclusion}

This small pilot study has shown that story writing might be a helpful way for nurse educators to understand the multiple factors which support or impede student placement learning. Current placement learning evaluation methods are helpful for educators to understand students' placement learning experiences. However the use of stories adds a further dimension and helps uncover the multifaceted nature of learning in the clinical setting.

\section{References}

Andrew, N., McGuinness, C., Reid, G. and Corcoran, T. (2009) 'Greater than the sum of its parts: transition into the first year of undergraduate nursing', Nurse Education in Practice, 9(1), pp. 13-21. http://dx.doi.org/10.1016/j.nepr.2008.03.009 
Anthony, M. and Yastick, J. (2011) 'Nursing students' experiences with incivility in clinical education', Journal of Nursing Education, 50(3), pp. 140-144.

http://dx.doi.org/10.3928/01484834-20110131-04

Cheung, R.Y.M. and Au, T.K. (2011) 'Nursing students' anxiety and clinical performance', Journal of Nursing Education, 50(5), pp. 286-289. http://dx.doi.org/10.3928/01484834-20110131-08

Frank, A.W. (2010) Letting stories breathe: a socio-narratology. Chicago: University of Chicago Press.

Gorostidi, X.Z., Egilegor, X.H., Erice, M.J.A., Iturriotz, M.J.U., Garate, I.E., Lasa, M.B. and Cascante, X.S. (2007) 'Stress sources in nursing practice. Evolution during nursing training', Nurse Education Today, 27(7), pp. 777-787. http://dx.doi.org/10.1016/i.nedt.2006.10.017

Hamshire, C., Willgoss, T.G. and Wibberley, C. (2013) 'What are reasonable expectations? Healthcare student perceptions of their programmes in the North West of England', Nurse Education Today, 33(2), pp. 173-179. http://dx.doi.org/10.1016/j.nedt.2012.02.014

Holstein, J.A. and Gubrium, J.F. (2000) The self we live by: narrative identity in a postmodern world. New York: Oxford University Press.

Khater, W.A., Akhu-Zaheya, L.M. and Shaban, I.A. (2014) 'Sources of stress and coping behaviours in clinical practice among baccalaureate nursing students', International Journal of Humanities and Social Science, 4(6), pp. 194-202. Available at: http://www.ijhssnet.com/journals/Vol 4 No 6 April 2014/20.pdf

Killam, L.A. and Heerschap, C. (2013) 'Challenges to student learning in the clinical setting: a qualitative descriptive study', Nurse Education Today, 33(6), pp. 684-691. http://dx.doi.org/10.1016/j.nedt.2012.10.008 
Koch, T. (1998) 'Story telling: is it really research?', Journal of Advanced Nursing, 28(6), pp. 1182-1190.

Levett-Jones, T., Lathlean, J., Higgins, I. and McMillan, M. (2009) 'Staff-student relationships and their impact on nursing students' belongingness and learning', Journal of Advanced Nursing, 65(2), pp. 316-324. http://dx.doi.org/10.1111/j.13652648.2008.04865.x

McGowan, B. (2006) 'Who do they think they are? Undergraduate perceptions of the definition of supernumerary status and how it works in practice', Journal of Clinical Nursing, 15(9), pp. 1099-1105. http://dx.doi.org/10.1111/j.1365-2702.2005.01478.x

Nursing and Midwifery Council (NMC) (2010) Standards for Pre-Registration Nursing Education. London: NMC. Available at: https://www.nmc.org.uk/globalassets/sitedocuments/standards/nmc-standards-forpre-registration-nursing-education.pdf

Orland-Barak, L. and Wilhelem, D. (2005) Novices in clinical practice settings: student nurses' stories of learning the practice of nursing', Nurse Education Today, 25(6), pp. 455-464. http://dx.doi.org/10.1016/j.nedt.2005.04.006

Spencer, L., Ritchie, J., Ormston, R., O'Connor, W. and Barnard, M. (2013) 'Analysis: principles and processes', in Ritchie, J., Lewis, J., Mcnaughton-Nicholls, C. and Ormston, R. (eds.) Qualitative research practice: a guide for social science students and researchers. $2^{\text {nd }}$ edn. London: Sage, pp. 269-93.

Ritchie, J. and Spencer, L. (1994) 'Qualitative data analysis for applied policy research', in: Bryman, A. and Burgess, B. (eds.) Analyzing qualitative data. London: Routledge, pp. 173-194.

Warne, T., Johansson, U.B., Papastavrou, E., Tichelaar, E., Tomietto, M., den Bossche, K.V., Moreno, M.F.V. and Saarikoski, M. (2010) 'An exploration of the clinical learning experience of nursing students in nine European countries', Nurse Education Today, 30(8), pp. 809-815. http://dx.doi.org/10.1016/j.nedt.2010.03.003 


\section{Author details}

Dr Kirsten Jackis a Senior Lecturer in Adult Nursing at Manchester Metropolitan University. Her research interests lie in the emotional nature of nursing, and the ways in which educators can support nurses using innovative teaching and learning methods.

Dr Claire Hamshire is a Senior Learning and Teaching Fellow at Manchester Metropolitan University. Her research interests include student engagement, student attrition and learning transitions 